\title{
Equilibrium study of single and binary adsorption of lead and mercury on bentonite-alginate composite: Experiments and application of two theoretical approaches
}

\author{
Lotfi Sellaoui $^{\text {a,* }}$, Felycia Edi Soetaredjo ${ }^{\text {b }}$, Suryadi Ismadji ${ }^{\text {b }}$, Yacine Benguerba ${ }^{\text {c,d }}$, Guilherme L. Dotto ${ }^{\text {e }}$, \\ Adrián Bonilla-Petriciolet ${ }^{\mathrm{f}}$, Alírio E. Rodrigues ${ }^{\mathrm{g}}$, Abdelmottaleb Ben Lamine ${ }^{\mathrm{a}}$, Alessandro Erto ${ }^{\mathrm{h}}$ \\ a Unité de Recherche de Physique Quantique, UR 11 ES 54, Université de Monastir, Faculté des Sciences de Monastir, Tunisia \\ ${ }^{\mathrm{b}}$ Department of Chemical Engineering, Widya Mandala Surabaya Catholic University, 601-14 Surabaya, Indonesia \\ c Department of Processes Engineering, Universite Ferhat Abbas, Setif-1, 19000 Setif, Algeria \\ d Laboratoire de Génie des Procédés Chimiques, Université Ferhat Abbas, Sétif-1, 19000 Sétif, Algeria \\ e Environmental Processes Laboratory, Chemical Engineering Department, Federal University of Santa Maria-UFSM, 1000, Roraima Avenue, 97105-900 Santa Maria, RS, Brazil \\ ${ }^{\mathrm{f}}$ Instituto Tecnológico de Aguascalientes, Aguascalientes 20256, Mexico

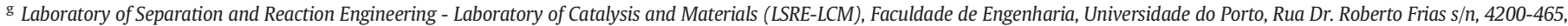 \\ Porto, Portugal \\ h Dipartimento di Ingegneria Chimica, dei Materiali e della Produzione Industriale, Università di Napoli Federico II, P.leTecchio, 80, 80125 Napoli, Italy
}

\section{A R T I C L E I N F O}

\section{Article history:}

Received 9 December 2017

Received in revised form 22 December 2017

Accepted 8 January 2018

Available online 10 January 2018

\section{Keywords:}

Single and competitive adsorption

Heavy metals

Bentonite-alginate composite

Mercury

Lead

\begin{abstract}
A B S T R A C T
The adsorption of $\mathrm{Pb}$ (II) and $\mathrm{Hg}$ (II) ions on bentonite-alginate composite (BAC) is investigated in both singlecompound and binary systems, at three different temperatures. For a better interpretation and comparison, all the adsorption equilibrium isotherms are recorded under identical conditions. A simple examination of all adsorption equilibrium isotherms shows that the bentonite-alginate composite is more effective for $\mathrm{Pb}$ (II) adsorption than for $\mathrm{Hg}$ (II) and the adsorption capacity is reduced in binary system, reflecting a competitive effect between the $\mathrm{Pb}$ (II) and $\mathrm{Hg}$ (II). To explain the single and binary processes and the corresponding mechanisms, Hill and competitive Hill models are applied. The adsorption geometry can be determined at different temperatures by an estimation of the number of ions captured per BAC adsorbent site. Based on these models, it is shown that the affinity sequence in all adsorption systems is: $\mathrm{Pb}$ (II) - Hg (II). This behavior can be explained and corroborated by an energetic analysis deduced from these models. Finally, in order to deepen the interpretation of single-compound and binary adsorption, the conductor-like screening model (COSMO-RS) was tested and applied to calculate the total interaction energies between heavy metals and BAC adsorbent. The evaluation of energies deduced from COSMO-RS model indicated that the electrostatic misfit interaction energy may play the main role in the heavy metals ions adsorption in tested systems.
\end{abstract}

(C) 2018 Elsevier B.V. All rights reserved.

\section{Introduction}

Adsorption has established as a very reliable process for both liquid and gas treatment, currently adopted in the framework of innovative technologies for the capture of both classical and emerging pollutants [1-4]. The interest in adsorption has significantly increased thanks to its versatility, which allows applying this technology for the removal of both organic and inorganic pollutants [5,6]. Moreover, adsorption can be adopted as a refining method for the remediation of polluted water or soils when recalcitrant or persistent pollutants are present $[7,8]$.

\footnotetext{
* Corresponding author at: Faculty of Sciences of Monastir, 5000 Monastir, Tunisia E-mail address: sellaouilotfi@yahoo.fr (L. Sellaoui).
}

The design of adsorption units mainly depends on adsorbent capacity in equilibrium conditions and their performance is influenced by the multicomponent competitive interactions of the compounds simultaneously present in solution. In this sense, multicomponent adsorption is the most realistic application, which deserves specific attention and dedicated investigation $[9,10]$. In fact, when the complexity of an adsorption system increases (e.g., when many adsorbates are simultaneously present in the solution), new issues arise and both theoretical and experimental studies are needed for a proper description of the mutual interactions between the adsorbates. Hence, the assessment of the adsorption capacity of a compound in the presence of other solutes as well as the definition of appropriate theoretical models is necessary for a proper design of a cost-effective depuration system [11,12]. In the latest years, many efforts have been made by our research group for the individuation of reliable models able to describe, under the 
same hypothesis, the single-compound and multicomponent adsorption, in order to define their competitive relationships [13,15]. However, one of the main issues dealing with adsorption is that each adsorption system can behave differently and a dedicated study for each of them can be required. In particular, dealing with heavy metals, their competitive adsorption cannot be predicted from specific chemical properties, such as water solubility, as for organic compounds [16].

Based on these considerations, the main objective of the present paper was to evaluate the $\mathrm{Pb}$ (II) and $\mathrm{Hg}$ (II) adsorption capacity onto bentonite-alginate composite (BAC) in both single-compound and binary adsorption systems, coupled with an accurate experimental and theoretical interpretation of data. Many different adsorbents were proposed in the literature for the single-compound capture of these heavy metals, while less studies deal with the binary system $[12,17-19]$. In particular, the use of bentonite or modified bentonite resulted in many published papers, in which the analysis of the adsorption mechanisms has been stressed [20,21]. However, in this case the studies on multicomponent systems are also limited and, at the best of our knowledge, absent for this adsorption system (i.e. $\mathrm{Pb}(\mathrm{II}) / \mathrm{Hg}$ (II) mixture - BAC).

In general, the literature indicated that heavy metal multicomponent systems are mainly described by the presence of competition effect between the adsorbates [22-24]. In fact, when the simultaneous adsorption of heavy metals is compared with their single-compound counterparts, their adsorption capacity can be strongly reduced. To this aim, a modeling description of multicomponent data able to correctly address this competition is of fundamental importance.

In this paper, a series of adsorption equilibrium isotherms of $\mathrm{Pb}$ (II) and $\mathrm{Hg}$ (II) on BAC in single-compound and binary systems were realized under identical experimental conditions for the sake of comparison. Far to the classical models and to well quantify the interference of one metal with the adsorption of the other, Hill and competitive Hill models previously published $[15,17]$ were adopted and applied in this paper. The models containing several parameters having the same physicochemical aspect classified in two types (steric and energetic), which can be proficiently adopted to explain the single-compound and simultaneous adsorption mechanism in the same framework. Importantly, an energetic study based on these models was developed in detail to identify the interactions between the heavy metals and the adsorbent surface, for a thorough characterization of the adsorption phenomena. Finally, the conductor-like screening model for real solvents (COSMO-RS) model was also applied to calculate the total interaction energy between these heavy metals and the adsorbent surface and also to select the most influent factor promoting $\mathrm{Pb}$ (II) and $\mathrm{Hg}$ (II) adsorption onto BAC.

\section{Experimental}

\subsection{Materials}

Bentonite used in this study was obtained from bentonite mining located in Pacitan, East Java, Indonesia. Food grade sodium alginate was obtained from the local distributor of food ingredients in Surabaya, Indonesia. $\mathrm{Pb}\left(\mathrm{C}_{2} \mathrm{H}_{3} \mathrm{O}_{2}\right)_{2} \cdot 3 \mathrm{H}_{2} \mathrm{O}, \mathrm{HgCl}_{2}, \mathrm{H}_{2} \mathrm{SO}_{4}, \mathrm{NaOH}$, and $\mathrm{CaCl}_{2}$ were obtained from Merck (Merck Co., Germany) as AR grade.

\subsection{Acid activation of bentonite}

Raw bentonite was dried in a forced circulation oven at $110^{\circ} \mathrm{C}$ until its moisture content was around $10 \%$. Subsequently, the dried bentonite was pulverized in a JANKE \& KUNKEL Hammermill to reduce the particle size from 1 to $2 \mathrm{~cm}$ to $0.149 \mathrm{~mm}-0.125 \mathrm{~mm}$. Dried bentonite powder was then purified with hydrogen peroxide solution (30\%) at $30{ }^{\circ} \mathrm{C}$ to remove the organic impurities. The excess hydrogen peroxide in the mixture was removed by heating the system at $50{ }^{\circ} \mathrm{C}$. After the excess hydrogen peroxide was removed, the bentonite was washed with reverse osmosis water and dried in an oven at $110^{\circ} \mathrm{C}$ for $24 \mathrm{~h}$.

Subsequently, the bentonite was activated using $2 \mathrm{~N}$ of $\mathrm{H}_{2} \mathrm{SO}_{4}$ solution. The acid activation of bentonite was carried out according to the following procedure: $100 \mathrm{~g}$ of hydrogen peroxide pretreated bentonite were immersed into $500 \mathrm{~mL}$ of $\mathrm{H}_{2} \mathrm{SO}_{4}$ solution. During the acid activation process, the bentonite slurry was stirred at $200 \mathrm{rpm}$ using mechanical stirrer. The acid activation process was conducted at $60{ }^{\circ} \mathrm{C}$ for $5 \mathrm{~h}$. After the acid activation process was completed, the slurry was repeatedly washed with reverse osmosis water until the $\mathrm{pH}$ of the rinse water was constant.

\subsection{Preparation of bentonite - alginate composite}

The following procedure was employed to prepare bentonite - alginate composite (BAC): sodium alginate solution $(2 \% \mathrm{w} / \mathrm{v})$ was prepared by dissolving $2.5 \mathrm{~g}$ of sodium alginate into $100 \mathrm{~mL}$ of deionized water. Subsequently, $2.0 \mathrm{~g}$ of bentonite was added to the sodium alginate solution and stirred at $500 \mathrm{rpm}$ for $3 \mathrm{~h}$ at $50{ }^{\circ} \mathrm{C}$. Before the addition of $\mathrm{CaCl}_{2}$ to form gel spheres, the mixture was irradiated in a microwave oven ( 700 watt, $60 \mathrm{~s}$ ). The formation of gel spheres was conducted by addition of calcium chloride solution into bentonite - sodium alginate mixture (drop by drop). The gel spheres of bentonite - alginate composite were repeatedly washed using deionized water to remove the excess of calcium chloride solution and dried in an oven at $50{ }^{\circ} \mathrm{C}$ for $48 \mathrm{~h}$. Dried bentonite - alginate composite was stored in a desiccator until further use.

\subsection{Characterization of $B A C$}

X-Ray diffraction (XRD), nitrogen adsorption and Fourier Transform Infrared Spectroscopy (FTIR) analyses were employed to characterize the structure of bentonite - alginate composite. The XRD analysis was performed on a Philips X'pert Xray Diffractometer. The XRD patterns of the solid sample was acquired at $40 \mathrm{kV}$ and $30 \mathrm{~mA}$, using $\mathrm{Cu} K \alpha 1$ $(\lambda=0.15405 \mathrm{~nm})$ as the source of radiation. Micromeritics ASAP 2010 sorption analyzer was used to obtain the nitrogen adsorption isotherm of the sample. $\mathrm{N}_{2}$ adsorption isotherm was obtained at the boiling point of nitrogen $\left(-176{ }^{\circ} \mathrm{C}\right)$ and relative pressure $\left(p / p^{\circ}\right)$ of 0.001 to 0.998 . The surface functional groups of the sample were obtained using Shimadzu/FTIR-8400S spectrometer. The KBr pellet method was employed to obtain the FTIR spectrum of the composite.

\subsection{Metals adsorption experiments}

The adsorption studies of $\mathrm{Hg}$ (II) and $\mathrm{Pb}$ (II) onto bentonite - alginate composite were conducted in a static mode at three different temperatures $\left(30,40\right.$, and $\left.50{ }^{\circ} \mathrm{C}\right)$. For single metal adsorption, the initial concentration of metal and $\mathrm{pH}$ of the solution were $300 \mathrm{mg} / \mathrm{L}$ and 6 , respectively. The procedure for the adsorption experiment of single metal is as follows: different masses of the BAC were added to a series of Erlenmeyer flasks, each flask containing $100 \mathrm{~mL}$ of metal solution. During the adsorption process, the temperature of the system was maintained at a desired temperature (i.e., 30,40 or $50^{\circ} \mathrm{C}$ ) using a thermal controller shaker water bath (Memmert) and shaken at $200 \mathrm{rpm}$. After the equilibrium time $(6 \mathrm{~h})$, the adsorbent was removed from the solution by centrifugation, and the equilibrium concentration of the metal was analyzed using an atomic absorption spectrophotometer (Shimadzu). The amount of metal adsorbed at equilibrium condition $\left(q_{e}\right)$ was calculated by the following equation $[35,36]$ :

$Q_{e}=\frac{\left(C_{o}-C_{e}\right)}{m} V$

where $C_{o}$ and $C_{e}$ are the initial and equilibrium concentration in $\mathrm{mg} / \mathrm{L}$, respectively, $m$ is the mass of BAC in $g$ and $V$ is volume of the solution 
in L. A similar procedure was employed for the adsorption of heavy metals in the binary system. The initial concentrations of both metals were $300 \mathrm{mg} / \mathrm{L}$.

\section{Characteristics of bentonite - alginate composite}

The XRD spectrum of bentonite - alginate composite is given in Fig. 1 It can be observed that montmorillonite and quartz (impurity) are dominant compounds in the structure of composite. The characteristic peaks of montmorillonite were observed at $2 \theta=6.27,20.18,30.06,35.28$, and $60.25^{\circ}$. The basal spacing of bentonite - alginate composite at $2 \theta=6.27^{\circ}$ corresponds to $\mathrm{d}_{001}=1.38 \mathrm{~nm}$.

In general, the adsorption of heavy metal onto bentonite - alginate composite involved several adsorption mechanisms such as electrostatic interaction, van der Waals interaction, etc. Based on the FTIR analysis, several functional groups were observed on the surface of bentonite - alginate composite, which can be involved in the adsorption of heavy metals. These include $(\mathrm{Si}, \mathrm{Al})-\mathrm{OH}$ stretching $\left(3639 \mathrm{~cm}^{-1}\right)$, -OH stretching $\left(3236 \mathrm{~cm}^{-1}\right), \mathrm{COO}-$ stretching $\left(1624 \mathrm{~cm}^{-1}\right), \mathrm{CH}_{2}$ bending vibration $\left(1423 \mathrm{~cm}^{-1}\right)$, and $\mathrm{R}-\mathrm{O}-\mathrm{R}$ stretching $\left(1407 \mathrm{~cm}^{-1}\right)$. FTIR spectra were determined also for BAC sample after singlecompound adsorption of both $\mathrm{Pb}(\mathrm{II})$ and $\mathrm{Hg}(\mathrm{II})$, as reported in Fig. 2.

For a thorough analysis of FTIR spectra, it is important observing that all the adsorption experiments were conducted at a $\mathrm{pH}$ above the $\mathrm{pH}_{\mathrm{pzc}}$ of $\mathrm{BAC}$ (being $\mathrm{pH}_{\mathrm{pzc}}$ of the $\mathrm{BAC}$ equal 5.2). The $\mathrm{pH}_{\mathrm{pzc}}$ of $\mathrm{BAC}$ was determined using the $\mathrm{pH}$-drift procedure [25]. In this condition, the BAC adsorbent has a negative charge on its surface, which enhances the adsorption of metal ion through electrostatic interaction. In the spectra of $\mathrm{Pb}$ (II) and $\mathrm{Hg}$ (II) loaded composite, the interactions of both heavy metals with the surface of the composite were testified by the decrease of intensity and wavenumber shifting of $\mathrm{COO}$ - stretching functional group (Fig. 2). Furthermore, the peak corresponding to - $\mathrm{OH}$ stretching group ( $3236 \mathrm{~cm}^{-1}$ ) shifts to $3202 \mathrm{~cm}^{-1}$ ( $\mathrm{Pb}$ (II) loaded composite) and $3286 \mathrm{~cm}^{-1}$ ( $\mathrm{Hg}$ (II) loaded composite), this phenomenon indicating that - $\mathrm{OH}$ surface functional groups also responsible for the adsorption of $\mathrm{Pb}(\mathrm{II})$ and $\mathrm{Hg}(\mathrm{II})$.

The BET surface area and pore volume of bentonite - alginate composite were equal to $56.8 \mathrm{~m}^{2} / \mathrm{g}$ and $0.085 \mathrm{~cm}^{3} / \mathrm{g}$, respectively. After the adsorption process, the $\mathrm{Pb}$ (II) loaded composite has a BET surface area and pore volume of $53.7 \mathrm{~m}^{2} / \mathrm{g}$ and $0.078 \mathrm{~cm}^{3} / \mathrm{g}$, respectively. The $\mathrm{Hg}$ (II) loaded composite showed a BET surface area and pore volume of $54.8 \mathrm{~m}^{2} / \mathrm{g}$ and $0.081 \mathrm{~cm}^{3} / \mathrm{g}$, respectively. It can be concluded that, slightly decreases of BET surface area and pore volume occurred after the adsorption, possibly due to the occupation of some interlayer spacing of bentonite in the composite by metals ions.

\section{4. $\mathrm{Pb}(\mathrm{II})$ and $\mathrm{Hg}(\mathrm{II})$ adsorption isotherms}

The adsorption isotherms of single-compound and binary systems are reported in Fig. 3. From a general point of view, it can be observed that the isotherm shape of all the investigated systems are monothonic with equilibrium concentration and only in few cases an asympthotic value of adsorption capacity is reached (e.g. for $\mathrm{Pb}(\mathrm{II})$ at $50{ }^{\circ} \mathrm{C}$ ). Moreover, adsorption capacity increases with temperature, testifying an endothermic character of adsorption.

Despite the simple form of adsorption equilibrium isotherms, which is common in several systems of heavy metals adsorption $[22,23]$ specific information about the adsorption mechanisms can be retrieved by a modeling approach based on statistical physics. In fact, the increase in adsorption capacity leads to an occupied receptor sites/pores by $\mathrm{Pb}$

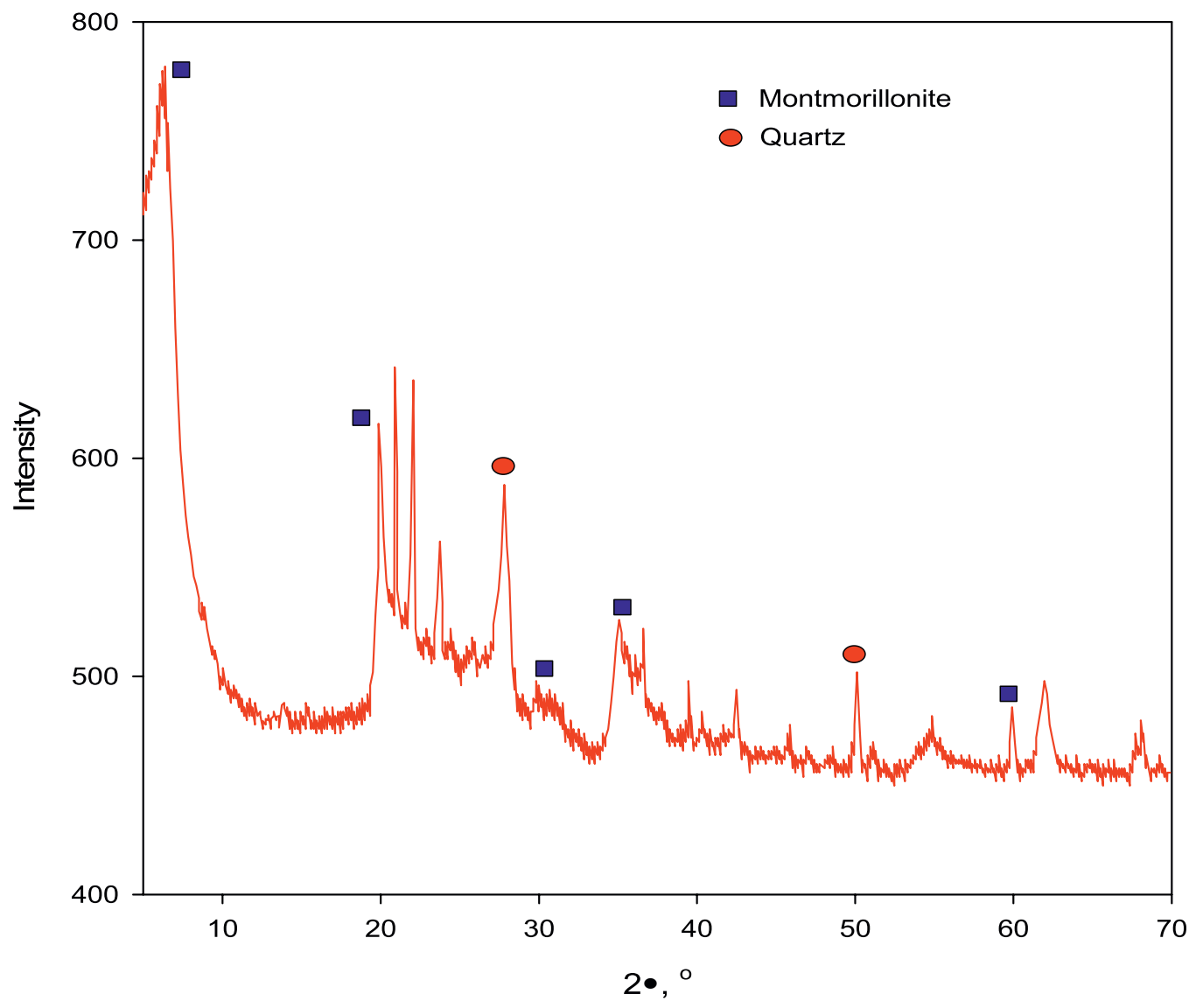

Fig. 1. The XRD spectrum of bentonite - alginate composite. 

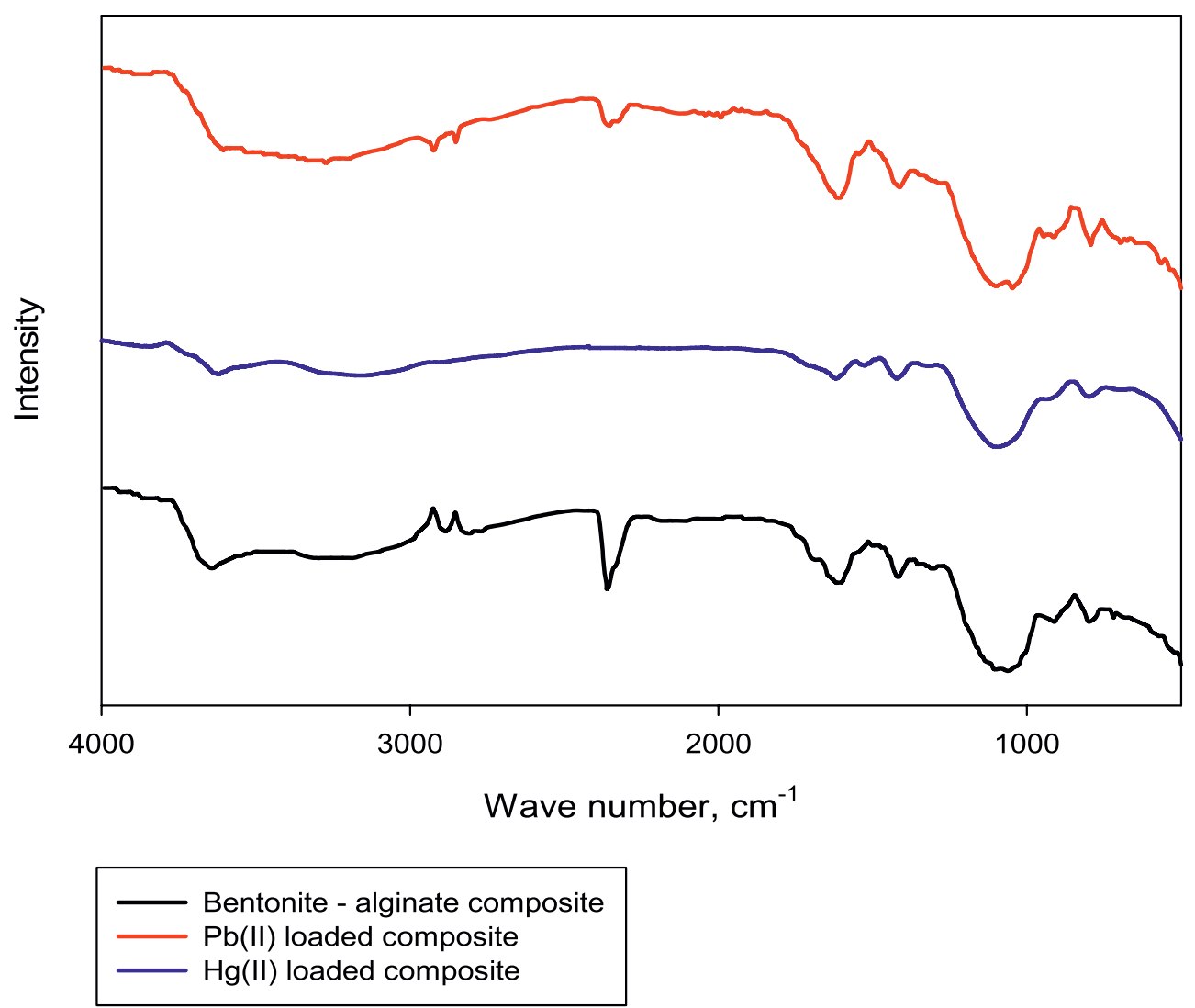

Fig. 2. FTIR spectra of bentonite - alginate composite and metals loaded composite.

(II) and $\mathrm{Hg}$ (II) metals of bentonite-alginate composite (BAC) and each site/pore can reasonably accepts a fraction of ion, one ion, or more. Analytically, the occupation of BAC receptor site by $\mathrm{Pb}$ (II) and $\mathrm{Hg}$ (II) heavy metals ions was illustrated by $n$ and $n_{i}$ parameters defined as the number of ions captured by BAC receptor sites in singlecompound and binary system, respectively. However, even if these two parameters are steric, the studies of adsorption phenomena by statistical physics models $[14,15]$ demonstrated that these parameters play an important role in explaining the adsorption mechanism but they are not dominant.

From Fig. 1, it can be observed another important result. In singlecompound systems, the adsorption capacity of $\mathrm{Pb}$ (II) is higher than $\mathrm{Hg}$ (II) and for all the investigated temperatures. According to the literature, this difference could be explained by the physicochemical properties of adsorbates and adsorbent [26] and by differences in the interaction energies between the adsorbates and the adsorbent surface $[14,15]$. Furthermore, the adsorption of $\mathrm{Hg}$ (II) was significantly influenced by the presence of $\mathrm{Pb}$ (II) in binary systems. This behavior is mirrored by a reduction in the adsorption capacity of both $\mathrm{Pb}$ (II) and $\mathrm{Hg}$ (II) compared to their single-compound counterparts. Hence, a limitative effect was created between these heavy metals during the simultaneous adsorption. Theoretically, it is possible to examine the adsorption phenomena and mechanisms of the single-compound and binary adsorption by testing two models developed using statistical physics, derived by application of grand canonical ensemble. Moreover, the conductor like screening model for real solvents (COSMO-RS model) can be successfully applied in order to retrieve interesting information about the energetic character of adsorption, so to corroborate the statistical physics results.

\section{Model theory}

\subsection{Statistical physics models for single-compound and binary adsorption}

Hill and competitive Hill models built using grand canonical ensemble in statistical physics present several advantageous to elucidate the single-compound and binary adsorption. They are simple and very explicative containing some steric and energetic physicochemical parameters. The mathematical development of these models has been previously detailed $[15,27]$. The expression of Hill model is given in Eq. 2, and for competitive Hill model in Eqs. 3 and 4.

$$
\begin{aligned}
& Q=\frac{n N_{M}}{1+\left(\frac{c_{1 / 2}}{c_{e}}\right)^{n}} \\
& Q_{a 1}=\frac{n_{1} N_{M}\left(\frac{c_{e_{1}}}{c_{01}}\right)^{n_{1}}}{1+\left(\frac{c_{e_{1}}}{c_{01}}\right)^{n_{1}}+\left(\frac{c_{e_{2}}}{c_{02}}\right)^{n_{2}}} \\
& Q_{a 2}=\frac{n_{2} N_{M}\left(\frac{c_{e_{2}}}{c_{02}}\right)^{n_{2}}}{1+\left(\frac{c_{e_{1}}}{c_{01}}\right)^{n_{1}}+\left(\frac{c_{e_{2}}}{c_{02}}\right)^{n_{2}}}
\end{aligned}
$$

Eq. 2 represents the evolution of adsorption capacity as function of equilibrium liquid concentration in single-compound system. In this equation, $c_{1 / 2}$ and $c_{e}$ are the concentrations at half saturation and at equilibrium of the heavy metal considered, respectively, $\mathrm{n}$ is the number 

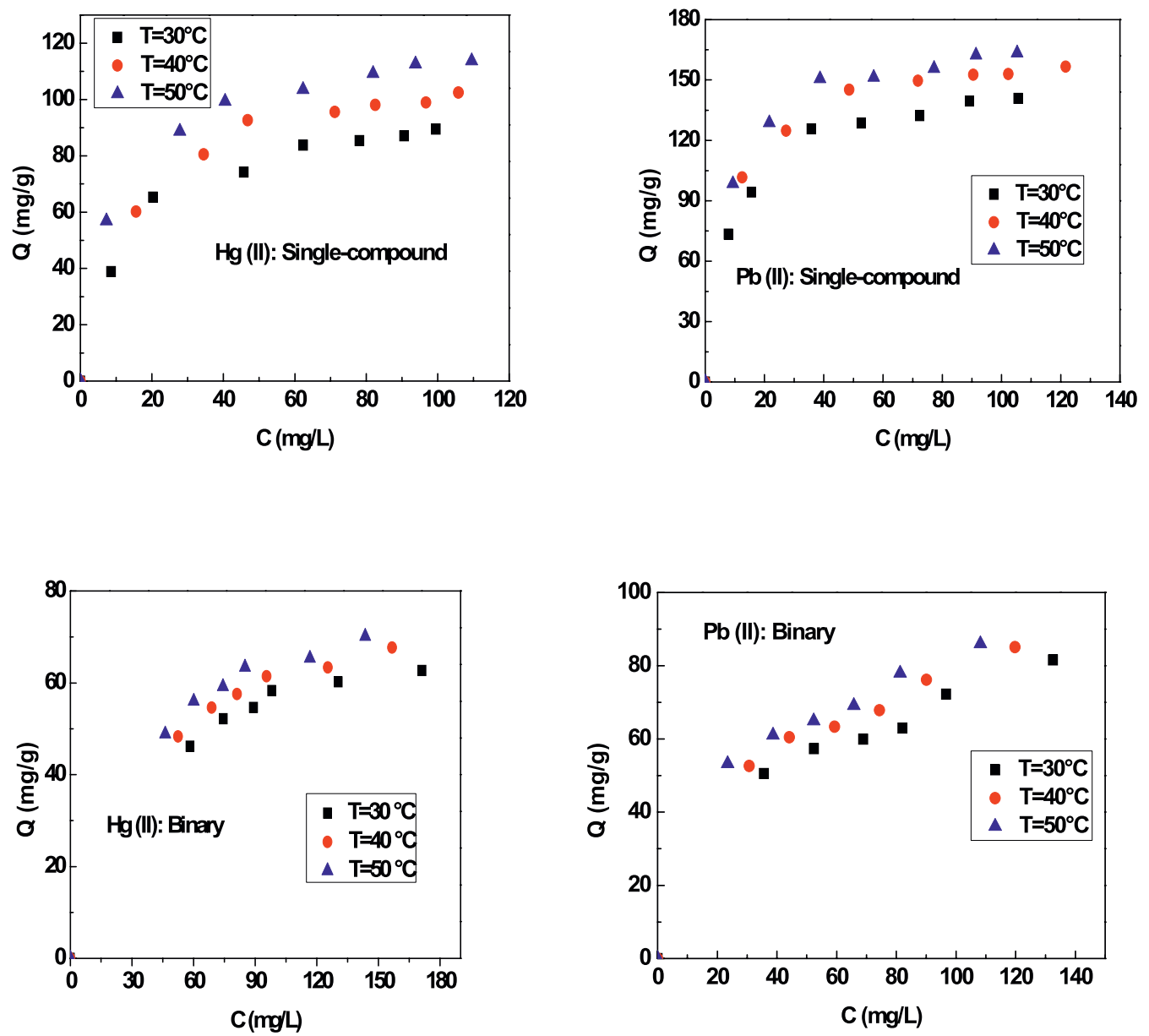

Fig. 3. Adsorption isotherms of $\mathrm{Hg}$ (II) and $\mathrm{Pb}$ (II) on BAC adsorbent in single-compound and binary systems at different temperatures.

of $\mathrm{Pb}$ (II) or $\mathrm{Hg}$ (II) ions captured per site and $\mathrm{N}_{\mathrm{M}}$ is the density of receptor sites. Similarly, Eqs. 3 and 4 express the equilibrium adsorption capacity in binary system as function of $\mathrm{Pb}$ (II) and $\mathrm{Hg}$ (II) equilibrium concentration. In these model expressions, $c_{01}$ and $c_{02}$ represent the concentrations at half saturation of each adsorbate, $c_{e 1}$ and $c_{e 2}$ are the heavy metal equilibrium concentrations and $\mathrm{n}_{1}$ and $\mathrm{n}_{2}$ are the number of $\mathrm{Pb}$ (II) and $\mathrm{Hg}$ (II) captured per adsorbent site. These models were applied to the experimental adsorption isotherms reported in Fig. 3 and the fitting results are listed in Table 1 by application the Levenberg Marquardt algorithm. The application of Levenberg Marquardt algorithm leads also to retrieve the values of the adjustment coefficient controlling the fitting quality. In all investigated systems, the $R^{2}$ values $\left(R^{2}\right.$ varies in this domain: 0.981-0.994) demonstrated an excellent correlation between the statistical physics models and the experimental data.

Table 1

Value of number of ions captured per BAC receptor site and adsorption capacity at saturation at different temperatures by Hill models, for $\mathrm{Pb}(\mathrm{II}) / \mathrm{Hg}(\mathrm{II})$ adsorption onto BAC.

\begin{tabular}{|c|c|c|c|c|c|c|}
\hline & & $\mathrm{Pb}(\mathrm{II})$ :single & & & $\mathrm{Hg}(\mathrm{II})$ :single & \\
\hline & $30^{\circ} \mathrm{C}$ & $40^{\circ} \mathrm{C}$ & $50{ }^{\circ} \mathrm{C}$ & $30^{\circ} \mathrm{C}$ & $40^{\circ} \mathrm{C}$ & $50^{\circ} \mathrm{C}$ \\
\hline $\mathrm{n}$ & 0.83 & 1.21 & 1.55 & 0.73 & 1.10 & 1.44 \\
\hline \multirow[t]{3}{*}{$\mathrm{Q}_{\text {sat }}(\mathrm{mg} / \mathrm{g})$} & 136.18 & 162.11 & 169.88 & 85.18 & 111.40 & 123.88 \\
\hline & & $\mathrm{Pb}(\mathrm{II})$ :binary & & & $\mathrm{Hg}(\mathrm{II})$ :binary & \\
\hline & $30{ }^{\circ} \mathrm{C}$ & $40^{\circ} \mathrm{C}$ & $50{ }^{\circ} \mathrm{C}$ & $30{ }^{\circ} \mathrm{C}$ & $40^{\circ} \mathrm{C}$ & $50{ }^{\circ} \mathrm{C}$ \\
\hline $\mathrm{n}_{\mathrm{i}}$ & 0.58 & 0.51 & 0.55 & 0.49 & 0.57 & 0.54 \\
\hline $\mathrm{Q}_{\mathrm{sat}}(\mathrm{mg} / \mathrm{g})$ & 88.18 & 94.94 & 100.05 & 58.58 & 66.13 & 75.74 \\
\hline
\end{tabular}

An example of adsorption isotherm fitting for each investigated system is reported in Supplementary file.

\subsection{COSMO-RS model}

The interaction energy of each adsorbate (Pb (II), $\mathrm{Hg}$ (II)) with BAC adsorbent can be predicted by the conductor like screening model for real solvents (COSMO-RS model). This model is able to predict several thermodynamic and physical properties but the phase behavior of pure fluids and/or mixtures requires the geometric coordinates of the individual atoms of each molecule or ion [28-31]. The COSMO-RS model combines quantum chemical approaches, based on the dielectric continuum model known as COSMO, with statistical thermodynamics calculations. In the COSMO calculations, the molecules or ions are surrounded by a virtual conductor environment, and the interactions are considered to take place on segments of this perfect/ideal conductor interface taking into account the electrostatic screening and the backpolarization of the solute molecule. Thus, the discrete surface around the solute molecule and each segment is characterized by their geometry and their local surface screening charge density $(\sigma)$ at a minimum energetic state of the conductor, stored in the COSMO files [28-31]. The complete description of the molecule is achieved by a distribution function $\mathrm{p}_{\mathrm{s}}(\sigma)$ of $\sigma$ over the whole surface of the molecule or ion (called $\sigma$-profile) that describes molecular interactions. Additionally, the COSMO-RS model considers three specific interaction energies of a molecule or ion with its environment, described as a function of the polarization charges of the two interacting segments- $\left(\sigma, \sigma^{\prime}\right)$ or $\left(\sigma_{\text {donors }}, \sigma_{\text {acceptors }}\right)$ : 


\section{Electrostatic misfit interaction:}

$E_{M F}\left(\sigma, \sigma^{\prime}\right)=a_{e f f}^{\alpha^{\prime}} /{ }_{2}\left(\sigma+\sigma^{\prime}\right)^{2}$

\section{Hydrogen -bonding energy:}

$E_{H B}=a_{\text {eff }} c_{H B} \min \left(0 ; \min \left(0, \sigma_{\text {donor }}+\sigma_{H B}\right) \max \left(0 ; \sigma_{\text {acceptor }}-\sigma_{H B}\right)\right)$

\section{Van der Waals energy:}

$E_{V d W}=a_{e f f}\left(\tau_{V d W}+\tau \prime_{V d W}\right)$

In these last expressions:

$a_{\text {eff }}$ represents the effective contact area between two surface segments; $\alpha^{\prime}$ is an interaction parameter; $c_{H B}$ is the hydrogen-bond strength; $\sigma_{H B}$ is the threshold for hydrogen-bonding; $\tau_{V d W}$ and $\tau^{\prime}{ }_{V d W}$ are element specific adjustable Van der Waals interaction parameters.

To apply the COSMO-RS model, the first step toward ground state geometry optimization of a molecule or ion is to build its 3D molecular structure. After building the structure of heavy metals and BAC adsorbent, geometry optimization was performed at the DFT (Density Functional Theory) level and def-TZVP (Triple Zeta for Valence Electrons plus Polarization Function) basis set for each compound. Both 3D molecular structures and its geometry optimization were conducted using Turbomole 6.4 software package (TmoleX). Conductor-like screening model (COSMO) calculations were then applied to generate a COSMO-files. The created COSMO-files of heavy metals ions and BAC adsorbent obtained after geometry optimization were imported by COSMOthermX software to combine the $\mathrm{Pb}$ (II) and $\mathrm{Hg}$ (II) with BAC adsorbent and to calculate the interaction energies.

\section{Results and discussions of heavy metal adsorption modeling}

6.1. Description of adsorption geometry of investigated adsorbates and effect of temperature

In the literature, the research works on heavy metals adsorption in single-compound and binary systems have been predominantly interpreted by Langmuir and extended Langmuir models [22, 23]. These models offer some advantages to elucidate the involved phenomena but they appear as limited. For example, these models assumed that the pore of each adsorbent can accept only one ion/molecule. In these conditions, it is reasonably to consider that the investigated adsorbates in each system adsorb with an inclined position [27]. Then, they are not able to properly describe the geometry of studied adsorbates and elucidate the temperature effect on this adsorption geometry. Hence, this general property can limit the description of the adsorption process. Hill and competitive Hill models represent the general case of the last models assuming that BAC accepts $n$ and $n_{i}$ heavy metals ions in single-compound and binary adsorption systems, respectively. Consequently, it is useful to describe the geometrical way by which $\mathrm{Pb}$ (II) and $\mathrm{Hg}$ (II) are adsorbed, at different temperatures. To this aim, the values of these two parameters must be determined and discussed. In the case $n$ or $n_{i}$ values are $<1$, each receptor site of BAC can accept a fraction of ion [32]. Therefore, the adsorption geometry is parallel [32]. In the case $n$ or $n_{i}$ values are higher or equal to 1, each receptor site of BAC can accept one or more ions. This case clearly indicated that the adsorption geometry is non-parallel [32]. All the values of $\mathrm{n}$ or $\mathrm{n}_{\mathrm{i}}$ for $\mathrm{Pb}$ (II) and $\mathrm{Hg}$ (II) estimated by fitting model were listed in Table 1. In singlecompound system, the values of $\mathrm{n}$ are higher than 1 indicating that this geometry is non-parallel i.e., one or more ion of $\mathrm{Pb}$ (II) or $\mathrm{Hg}$ (II) are fixed on the same receptor site, except at low temperature $(\mathrm{T}=$ $30{ }^{\circ} \mathrm{C}$ ). This result explained that the heavy metals were mainly adsorbed with inclined position on BAC. Differently, for binary system, all the values of $n_{i}$ are $<1$, hence the heavy metal ions are linked parallel to the adsorbent surface.

The evolution of this parameter with temperature is depicted in Fig. 4.

Adsorption geometry was significantly modified by the temperature, which indicated that $\mathrm{Pb}$ (II) and $\mathrm{Hg}$ (II) changed their adsorption geometries from parallel to non-parallel position. This adsorption geometry change can be likely ascribed to the increases of ion mobility when the temperature increases, which can determine a change in the adsorbates position on BAC. In binary adsorption systems, all the values of $n_{i}$ are less than unity, hence $\mathrm{Pb}$ (II) or $\mathrm{Hg}$ (II) are shared with practically two receptor sites since all the values are around to 0.5 . The behavior of $n_{i}$ evolution is mainly due to the competitive effect between these ions. Hence, an antagonistic effect was created between these ions on the same BAC receptor site. Regarding the evolution of $n_{i}$ (Fig. 4) with temperature, we noticed that this parameter evolves with an inverse manner, i.e. when the number of $\mathrm{Pb}$ (II) ion bonded per site $\left(\mathrm{n}_{1}\right)$ increases, the number of $\mathrm{Hg}$ (II) $\left(\mathrm{n}_{2}\right)$ decreases. This finding leads to the conclusion that temperature has a different effect on the two ions which is clearer during the competitive adsorption.

\subsection{Interpretation of adsorption capacity}

The evolution of the adsorption capacity at saturation of all the investigated systems is reported in Fig. 5, as a function of temperature. The first result of this evolution indicated that the single-compound and binary systems are both endothermic since the adsorption capacity increased with temperature. Moreover, in all the studied systems and based on our fitting results, $\mathrm{Pb}$ (II) adsorption capacity are higher than $\mathrm{Hg}$ (II), in both single-compound and binary systems. Classically and based on several published papers, in order to analyze and elucidate the effect of the second ion, it is possible to identify three interesting cases which are in relation with the ratio of binary $\left(\mathrm{Q}_{b}\right)$ to singlecompound $\left(\mathrm{Q}_{\mathrm{s}}\right)$ adsorption capacities [33].

(a) $Q_{b} / Q_{s}=1$ : this case clearly indicated that there is no significant interaction between $\mathrm{Pb}$ (II) and $\mathrm{Hg}$ (II). For this case, in general the evolution of the adsorption capacity as function of equilibrium concentration are relatively similar i.e., no strongly difference between the adsorption isotherms in single-compound and binary systems are present.

(b) $\mathrm{Q}_{b} / \mathrm{Q}_{s}>1$ : adsorption of $\mathrm{Pb}$ (II) ion is enhanced by the presence of $\mathrm{Hg}$ (II) ion or inversely. In this case, the synergetic effect could be promoted by the particular electric charge distribution induced by the first adsorbate, which could make a favorable environment to the adsorption of the other.

(c) $\mathrm{Q}_{b} / \mathrm{Q}_{\mathrm{s}}<1$ : the adsorption of $\mathrm{Pb}$ (II) ion is affected by $\mathrm{Hg}$ (II) or inversely. This case is typical of competition phenomena.

For all the investigated systems, resulted $\mathrm{Q}_{\mathrm{b}} / \mathrm{Q}_{\mathrm{s}}<1$. This result showed that a competitive effect arose in the adsorption between these two ions. For better details about competition grade, it is possible to estimate the ratio of number of ions captured by BAC receptor site in binary to single-compound systems. In fact, it was previously mentioned that all values of $n_{i}$ are inferior to $n$ (according also to Table 1 ), hence all the values of $n_{i} / n$ are inferior to unity confirming the antagonist effect.

In addition to this result, it was noticed that the values of the number of $\mathrm{Pb}$ (II) ions captured by BAC receptor sites are superior to the values of $\mathrm{Hg}$ (II). This evidence can be explained by some physicochemical properties of adsorbate or adsorbent like electronegativity, the type of functional groups etc. The conventional adsorption theory on solid surfaces indicates that heavy metals of higher electronegativity should adsorb more readily. Indeed, the electronegativity of $\mathrm{Pb}$ (II) (2.33) is higher than that of $\mathrm{Hg}$ (II) (2.0), hence the adsorption capacity of $\mathrm{Pb}$ (II) should be greater than that of $\mathrm{Hg}$ (II) which is in agreement with our results. 

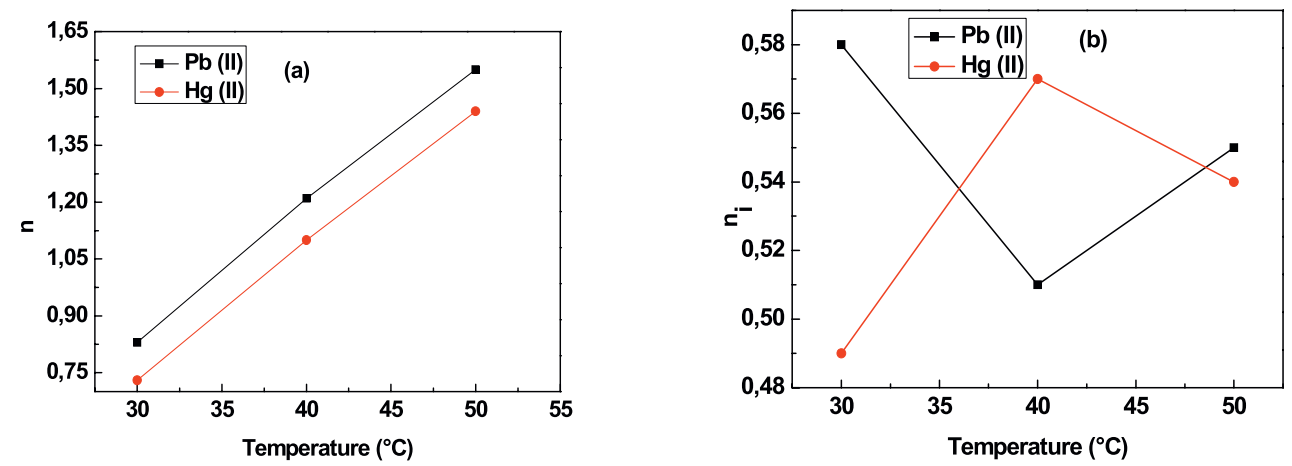

Fig. 4. Evolution of the number of heavy metals ions captured by BAC receptor site in single-compound (a) and binary (b) systems as function of temperature.

\subsection{Energetic investigation through statistical physics and COSMO-RS} models

In order to give further insights on the adsorption properties of the investigated systems, further energetic investigations were carried out.

The expressions of the adsorption energies from statistical physics models in single-compound and binary systems are given by [15]:

$\varepsilon=k_{B} T \ln \left(\frac{c_{S}}{c_{1 / 2}}\right)$

$\varepsilon_{i}=k_{B} T \ln \left(\frac{c_{s i}}{c_{i}}\right)$

in which $\mathrm{c}_{\mathrm{s}}$ is the solubility of the investigated adsorbate.

The investigation of the adsorption energy provides a direct characterization of the adsorption properties of the couple adsorbateadsorbent. The evolution the adsorption energies in single-compound and binary systems are depicted in Fig. 6 .

The calculation of adsorption energy that characterizes the $\mathrm{Pb}$ (II) and $\mathrm{Hg}$ (II) interactions with BAC adsorbent allowed retrieving interesting interpretations.

(a) The single-compound and binary adsorption could be a combination of physical and chemical adsorption mechanisms where the physisorption plays a relevant role since all the values are practically near to $20 \mathrm{~kJ} / \mathrm{mol}$ [34].

(b) All the investigated systems are endothermic, since the adsorption energies are positive confirming the evolution of adsorption capacities with temperature.

Moreover, adsorption energy increased as function of temperature in all the investigated systems. This evidence can be explained by increasing the adsorption capacity with temperature, hence the interaction of $\mathrm{Pb}$ (II) and $\mathrm{Hg}$ (II) with BAC adsorbent surface increased. Further comparisons can be done among the number of ions bonded per site, the adsorption capacity at saturation and also the adsorption

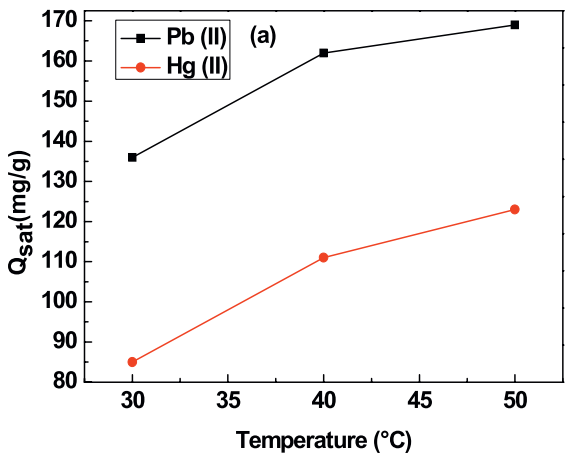

energies in single-compound and binary systems. It was noticed that when the number of ions bonded per site reduced, the adsorption capacity also reduced passing from single-compound to binary system. In parallel the adsorption energies reduced from single-compound to binary system. As a conclusion, we can understand that the adsorption energy is the dominant factor controlling both the single-compound and the simultaneous systems and represents the mainly reason for the reduction of adsorption capacity. For this reason, further investigations about the interaction energies are reported, based on COSMO-RS model application.

Among the advantages of the COSMO-RS model there is the ability to estimate all the energy types characterizing the interactions of $\mathrm{Pb}$ (II) and $\mathrm{Hg}$ (II) with its molecular environmental. In this paper, we limited to estimate the interaction energies of $\mathrm{Pb}$ (II) and $\mathrm{Hg}$ (II) with BAC receptor site for a better comparison with the results of statistical physics models. The calculation of interaction energies of $\mathrm{Pb}$ (II) and $\mathrm{Hg}$ (II) with BAC adsorbent specifies are of three types: Electrostatic misfit interaction, Hydrogen -bonding energy and Van der Waals energy. In order to estimate these energies, based on our experimental results, two molar fractions were used and directly normalized by COSMO-RS simulation. All the values of the three interaction energies are listed in Table 2. By evaluation of the values deduced from COSMO-RS model simulation, we can conclude that, in single-compound system, the total energy of adsorption $\mathrm{E}_{\mathrm{t}}$ of $\mathrm{Pb}$ (II) $\left(\mathrm{E}_{\mathrm{t}}=34.35 \mathrm{~kJ} / \mathrm{mol}\right)$ is higher than the total energy of $\mathrm{Hg}$ (II) $\left(\mathrm{E}_{\mathrm{t}}=21.44 \mathrm{~kJ} / \mathrm{mol}\right)$, which is in good agreement with the results obtained by the Hill model. On contrary, in binary system $\mathrm{E}_{\mathrm{t}}$ of $\mathrm{Hg}$ (II) is higher than $\mathrm{E}_{\mathrm{t}}$ of $\mathrm{Pb}$ (II). The latter result is probably due to the complexity of this system. Based on Table 2, it is clear that the Hydrogen -bonding energy has no contribution $\left(\mathrm{E}_{\mathrm{HB}}=0 \mathrm{~kJ} / \mathrm{mol}\right)$ in the heavy metals ions adsorption, in all investigated systems. This result is expected given the chemical structures of adsorbates. Comparing now the values of the Electrostatic misfit interaction and Van der Waals energies, it is clear that the Electrostatic misfit interaction energy plays the main role in the heavy metals ions adsorption in all investigated adsorption systems.

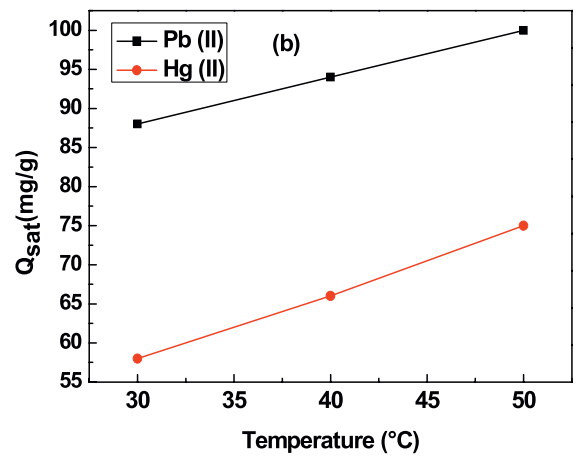

Fig. 5. Evolution of adsorption capacity at saturation with temperature for single-compound (a) and binary (b) systems. 

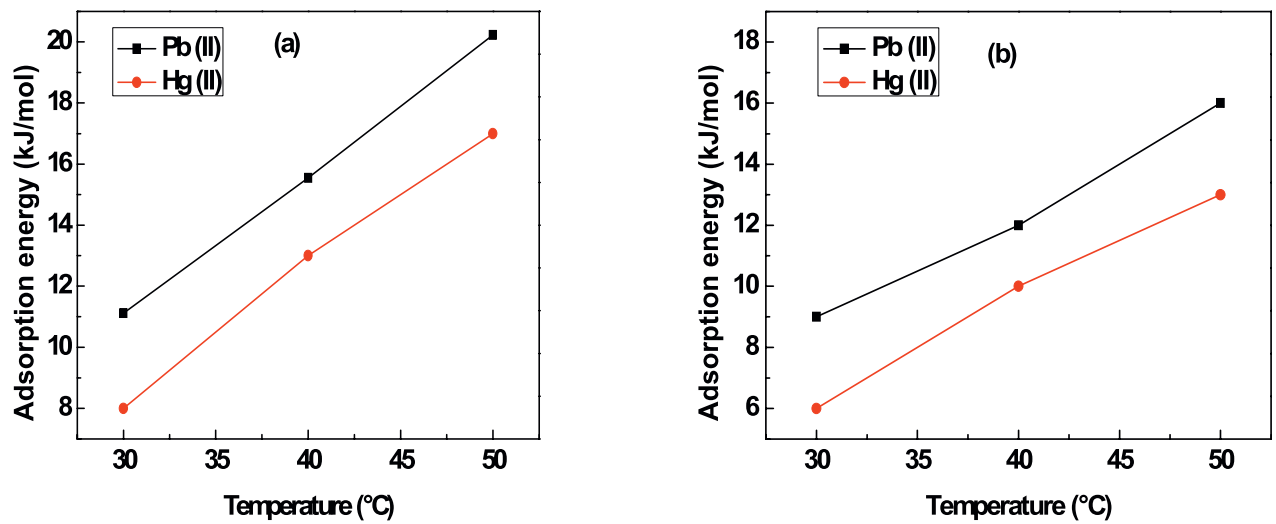

Fig. 6. Adsorption energy in single-compound (a) and binary (b) systems as a function of temperature.

\section{Conclusions}

In this work, the adsorption of $\mathrm{Pb}(\mathrm{II})$ and $\mathrm{Hg}$ (II) onto bentonitealginate composite (BAC) was studied in both single-compound and binary systems. Experimental results showed that $\mathrm{Pb}(\mathrm{II})$ was adsorbed more than $\mathrm{Hg}$ (II) and for both the compounds adsorption capacity increased with temperature. In binary system, a competition effect arose which affected the adsorption capacity of both the metal ions.

A first level analysis included the determination of FTIR spectra for BAC sample after single-compound adsorption of both $\mathrm{Pb}$ (II) and $\mathrm{Hg}$ (II). In the spectra of $\mathrm{Pb}$ (II) and $\mathrm{Hg}$ (II) loaded composite, the interactions of both heavy metals with the surface of the composite were testified by the decrease of intensity and wavenumber shifting of COOstretching functional group. Furthermore, the peak corresponding to $-\mathrm{OH}$ stretching group ( $3236 \mathrm{~cm}^{-1}$ ) shifts to $3202 \mathrm{~cm}^{-1}$ ( $\mathrm{Pb}$ (II) loaded composite) and $3286 \mathrm{~cm}^{-1}$ ( $\mathrm{Hg}(\mathrm{II})$ loaded composite), this phenomenon indicating that $-\mathrm{OH}$ surface functional groups also responsible for the adsorption of $\mathrm{Pb}(\mathrm{II})$ and $\mathrm{Hg}(\mathrm{II})$. BAC adsorbent has also a negative charge on its surface, which enhanced the adsorption of metal ion through electrostatic interaction.

Two theoretical approaches were developed in this paper to attribute new insights to $\mathrm{Pb}$ (II) and $\mathrm{Hg}$ (II) ions adsorption on BAC. The application of statistical physics models suggested that the investigated ions adsorb with parallel and non-parallel position on BAC adsorbent, in binary and single-compound systems, respectively. Adsorption geometry was significantly modified by the temperature, which indicated that $\mathrm{Pb}$ (II) and $\mathrm{Hg}$ (II) changed their adsorption geometries from parallel to non-parallel position. This adsorption geometry change can be likely ascribed to the increases of ion mobility when the temperature increases, which can determine a change in the adsorbates position on BAC. The investigation of the number of ions captured per adsorbent site demonstrated that an inhibition effect was manifested between the ions on the same receptor site. A clear reduction of the adsorption capacity of both ions in binary adsorption system confirmed the inhibition effect.

The evaluation of the adsorption energy by using Hill and competitive Hill models showed that the single-compound and binary adsorption could be a combination of physical and chemical interactions

Table 2

Values of interaction energies deduced from COSMO-RS simulation of all investigated adsorption systems

\begin{tabular}{lllll}
\hline & $\mathrm{Pb}(\mathrm{II})$ : single & $\mathrm{Hg}(\mathrm{II})$ : single & $\mathrm{Pb}(\mathrm{II})$ : binary & $\mathrm{Hg}(\mathrm{II})$ : binary \\
\hline $\mathrm{E}_{\mathrm{MF}}(\mathrm{kJ} / \mathrm{mol})$ & 45.89 & 29.84 & 21.56 & 29.63 \\
$\mathrm{E}_{\mathrm{VdW}}(\mathrm{kJ} / \mathrm{mol})$ & -11.56 & -8.36 & -9.48 & -8.36 \\
$\mathrm{E}_{\mathrm{HB}}(\mathrm{kJ} / \mathrm{mol})$ & 0 & 0 & 0 & 0 \\
$\mathrm{E}_{\mathrm{T}}(\mathrm{kJ} / \mathrm{mol})$ & 34.35 & 21.44 & 12.034 & 21.23 \\
\hline
\end{tabular}

where the physisorption may play a relevant role. Finally, the application of COSMO-RS indicated that the electrostatic misfit interaction energy plays the main role in the heavy metals ions adsorption, in all adsorption systems.

Supplementary data to this article can be found online at https://doi. org/10.1016/j.molliq.2018.01.056.

\section{References}

[1] A. Erto, A. Silvestre-Albero, J. Silvestre-Albero, F. Rodriguez-Reinoso, M. Balsamo, A. Lancia, F. Montagnaro, Carbon-supported ionic liquids as innovative adsorbents for CO2 separation from synthetic flue-gas, J. Colloid Interface Sci. 448 (2015) 41-50.

[2] W. Peng, H. Li, Y. Liu, S. Song, A review on heavy metal ions adsorption from water by graphene oxide and its composites, J. Mol. Liq. 230 (2017) 496-504.

[3] L. Sellaoui, E.C. Lima, G.L. Dotto, A. Ben Lamine, Adsorption of amoxicillin and paracetamol on modified activated carbons: Equilibrium and positional entropy studies, J. Mol. Liq. 234 (2017) 375-381.

[4] M. Balsamo, S. Cimino, G. de Falco, A. Erto, L. Lisi, Synergic effect of $\mathrm{Zn}$ and Cu oxides dispersed on activated carbon during reactive adsorption of $\mathrm{H}_{2} \mathrm{~S}$ adsorption at room temperature, Microporous Mesoporous Mater. 257 (2018) 135-146.

[5] C.F. Carolin, P.S. Kumar, A. Saravanan, G.J. Joshiba, M. Naushad, Efficient techniques for the removal of toxic heavy metals from aquatic environment: a review, J. Environ. Chem. Eng. 5 (3) (2017) 2782-2799.

[6] A. Erto, S. Chianese, A. Lancia, D. Musmarra, On the mechanism of benzene and toluene adsorption in single-compound and binary systems: energetic interactions and competitive effects, Desalin. Water Treat. 86 (2017) 259-265.

[7] H. Tang, C. Chang, L. Zhang, Efficient adsorption of $\mathrm{Hg}^{2+}$ ions on chitin/cellulose composite membranes prepared via environmentally friendly pathway, Chem. Eng. J. 173 (3) (2011) 689-697.

[8] S. Satyro, M. Race, F. Di Natale, A. Erto, M. Guida, R. Marotta, Simultaneous removal of heavy metals from field-polluted soils and treatment of soil washing effluents through combined adsorption and artificial sunlight-driven photochemical processes, Chem. Eng. J. 283 (2016) 1484-1493.

[9] K. Kadirvelu, Jyotsna Goel, C. Rajagopal, Sorption of lead, mercury and cadmium ions in multi-component system using carbon aerogel as adsorbent, J. Hazard. Mater. 153 (2008) 502-507.

[10] M. Vocciante, M. Trofa, T. D'Auria, L. Giraldo, P. Rodriguez-Estupiñan, J.C. Moreno Pirajan, A. Erto, A rigorous procedure for the design of adsorption units for the removal of cadmium and nickel from process wastewaters, J. Clean. Prod. 77 (2014) 35-46.

[11] R. Leyva-Ramos, L.A. Bernal-Jacome, R.M. Guerrero-Coronado, L. Fuentes-Rubio, Competitive adsorption of $\mathrm{Cd}(\mathrm{II})$ and $\mathrm{Zn}$ (II) from aqueous solution onto activated carbon, Sep. Sci. Technol. 36 (2001) 3673-3687.

[12] F. Di Natale, A. Erto, A. Lancia, D. Musmarra, Mercury adsorption on granular activated carbon in aqueous solutions containing nitrates and chlorides, J. Hazard. Mater. 192 (3) (2011) 1842-1850.

[13] A. Erto, F. Di Natale, D. Musmarra, A. Lancia, Modeling of single and competitive adsorption of cadmium and zinc onto activated carbon, Adsorption 21 (8) (2015) 611-621.

[14] L. Sellaoui, G.L. Dotto, A. Ben Lamine, A. Erto, Interpretation of single and competitive adsorption of cadmium and zinc on activated carbon using monolayer and exclusive extended monolayer models, Environ. Sci. Pollut. Res. 24 (24) (2017) 19902-19908.

[15] L. Sellaoui, F.E. Soetaredjo, S. Ismadji, E.C. Lima, G.L. Dotto, A. Ben Lamine, A. Erto, New insights into single-compound and binary adsorption of copper and lead ions on treated sea mango shell: experimental and theoretical studies, Phys. Chem. Chem. Phys. 19 (2017) 25927-25937.

[16] S. Kleineidam, C. Schuth, P. Grathwohl, Solubility-normalized combined adsorptionpartitioning sorption isotherms for organic pollutants, Environ. Sci. Technol. 36 (2002) 4689-4697. 
[17] Q. Feng, Q. Lin, F. Gong, S. Sugita, M. Shoya, Adsorption of lead and mercury by rice husk ash, J. Colloid Interface Sci. 278 (2004) 1-8.

[18] F.M. Francisca, D.A. Glatstein, Influence of $\mathrm{pH}$ and ionic strength on $\mathrm{Cd}, \mathrm{Cu}$ and $\mathrm{Pb}$ removal from water by adsorption in Na-bentonite, Appl. Clay Sci. 118 (2015) 61-67.

[19] S. Bao, K. Li, P. Ning, J. Peng, X. Jin, L. Tang, Highly effective removal of mercury and lead ions from wastewater by mercaptoamine-functionalised silica-coated magnetic nano-adsorbents: behaviours and mechanisms, Appl. Surf. Sci. 393 (2017) 457-466.

[20] J.i N. Bao, S.P. Putro, S. Santoso, Y.H. Ju Ismadji, Investigation of heavy metal adsorption in binary system by nanocrystalline cellulose - bentonite nanocomposite: improvement on extended Langmuir isotherm model, Microporous Mesoporous Mater. 246 (2017) 166-177.

[21] A.A. Taha, M.A. Shreadah, A.M. Ahmed, H.F. Heib, Multi-component adsorption of Pb (II), Cd(II), and $\mathrm{Ni}(\mathrm{II})$ onto Egyptian Na-activated bentonite; equilibrium, kinetics, thermodynamics, and application for seawater desalination, J. Environ. Chem. Eng. 4 (1) (2016) 1166-1180.

[22] V.C. Srivastava, I.D. Mall, I.M. Mishra, Equilibrium modeling of ternary adsorption of metal ions onto rice husk ash, J. Chem. Eng. Data 54 (2009) 705-711.

[23] V.C. Srivastava, I.D. Mall, I.M. Mishra, Removal of cadmium(II) and zinc(II) metal ions from binary aqueous solution by rice husk ash, Colloids Surf. A Physicochem. Eng. Asp. 312 (2008) 172-184.

[24] I.A. Aguayo-Villarreal, A. Bonilla-Petriciolet, R. Muñiz-Valencia, Preparation of activated carbons from pecan nutshell and its application in the antagonistic adsorption of heavy metal ions, J. Mol. Liq. 230 (2017) 686-695.

[25] P.C.C. Faria, J.J.M. Orfao, M.F.R. Pereira, Adsorption of anionic and cationic dyes on activated carbons with different surface chemistries, Water Res. 38 (2004) 2043-2052.

[26] T. Depci, Comparison of activated carbon and iron impregnated activated carbon derived from Gölbaşı lignite to remove cyanide from water, Chem. Eng. J. 181 (2012) 467-478.
[27] L. Sellaoui, T. Depci, A.R. Kul, S. Knani, A. Ben Lamine, A new statistical physics model to interpret the binary adsorption isotherms of lead and zinc on activated carbon, J. Mol. Liq. 214 (2016) 220-230.

[28] A. Klamt, COSMO-RS from Quantum Chemistry to Fluid Phase Thermodynamics and Drug Design, Elsevier, Amsterdam, 2005.

[29] A. Klamt, The COSMO and COSMO-RS solvation models, Wiley Interdiscip. Rev.: Comput. Mol. Sci. 1 (2011) 699-709.

[30] A. Klamt, F. Eckert, COSMO-RS: a novel and efficient method for the a priori prediction of thermophysical data of liquids, Fluid Phase Equilib. 172 (2000) 43-72.

[31] A. Klamt, F. Eckert, W. Arlt, COSMO-RS: an alternative to simulation for calculating thermodynamic properties of liquid mixtures, Annu. Rev. Chem. Biomol. Eng. 1 (2010) (2010) 101-122.

[32] L. Sellaoui, H. Guedidi, S. Knani, L. Reinert, L. Duclaux, A. Ben Lamine, Application of statistical physics formalism to the modeling of adsorption isotherms of ibuprofen on activated carbon, Fluid Phase Equilib. 387 (2015) 103-110.

[33] R. Tovar-Gomez, M.R. Moreno-Virgen, J. Moreno-Perez, A. Bonilla-Petriciolet, V. Hernandez-Montoya, C.J. Duran-Valle, Analysis of synergistic and antagonistic adsorption of heavy metals and dye acid blue 25 on activated carbon from multicomponent (ternary) systems, Chem. Eng. Res. Des. 93 (2015) 755-772.

[34] Y. Liu, Y.J. Liu, Biosorption isotherms, kinetics and thermodynamics. Separation and purification and, Technology 61 (2008) 229-242.

[35] E.C. Lima, J.L. Brasil, A.H.D.P. Santos, Evaluation of Rh, Ir, Ru, W-Rh,W-Ir, and W-Ru as permanent modifiers for the determination of lead in ashes, coals, sediments, sludges, soils, and freshwaters by electrothermal atomic absorption spectrometry, Anal. Chim. Acta 484 (2003) 233-242.

[36] E.C. Lima, M.A. Adebayo, F.M. Machado, in: C.P. Bergmann, M. FM (Eds.), Chapter 3Kinetic and Equilibrium Models of Adsorption in Carbon Nanomaterials as Adsorbents for Environmental and Biological Applications, Springer 2015, pp. 33-69. 